\title{
Princípios Organizadores das Representações de Rural e Cidade
}

\section{Mariana Bonomo ${ }^{1}$ \\ Lídio de Souza ${ }^{2}$ \\ Giannino Melotti ${ }^{3}$ \\ Augusto Palmonari ${ }^{4}$}

Resumo: O estudo foi desenvolvido com o propósito de conhecer os princípios que organizam as tomadas de posição de integrantes de um grupo rural em frente às representações de rural e cidade, a partir da análise dos processos de ancoragem psicológica, social e psicossocial. Foram realizadas entrevistas individuais com 200 integrantes de uma comunidade rural, distribuídos em quatro gerações. O roteiro foi composto por questões que focalizavam: (1) dados sociodemográficos referentes ao sexo, idade, geração e se o participante já havia vivido em áreas urbanas; (2) experiência de preconceito, expectativa de vida na cidade para não migrados e recomendação para viver na cidade pelos participantes que já tinham vivido em território urbano; (3) valores sociais do rural; e (4) evocações livres associadas aos objetos de representação. Os resultados, sistematizados por meio da Análise de Conteúdo e processados por meio do software SPAD-T, indicaram a presença de três princípios organizadores dos significados vinculados aos objetos rural vs. cidade: mundo natural vs. mundo artificial, vida feliz vs. vida ruim e quase autossuficiente vs. centro dos recursos. As discussões focalizaram as funções das representações nos processos de elaboração da identidade social, destacando-se entre elas a de produzir equilíbrio e sustentar a defesa do espaço de pertencimento.

Palavras-chave: Cidade, Princípios Organizadores, Representação Social, Ruralidade.

Abstract: From the analysis of the anchorage process, the study was designed to assess the principles that organize the positions taken by members of a rural group faced with rural/city representations. 200 representatives of four generations of a brazilian rural community took part in the study. The script for the interview was made up of questions which focused on: (1) socio-demographic data relating to sex, age, generation groups and previous experience of living in urban areas; (2) contact with prejudice, life expectancy in the city for non-migrants and recommendations on life in the city from participants who have already lived in urban areas; (3) rural social values; and (4) free evocations associated with objects of rural-urban representation. The results, synthesized using Content Analysis and SPAD-T software, indicated the presence of three organizing principles of the meaning of rural vs. city objects: natural world vs. artificial world, happy life vs. bad live and almost self-sufficient vs. resource centred. The function of the process of social iden-
Recebido:

04.11 .11

Aprovado:

11.11.12

1.Doutora em Psicologia,

professora colaboradora do Programa de Pós-Graduação em Psicologia

da Universidade Federal do Espírito Santo. E-mail: marianadalbo@gmail. com

2. Doutor em Psicologia Social, professor associado III do Departamento de Psicologia Social e do Desenvolvimento e do Programa de Pós-Graduação em Psicologia da Universidade Federal do Espírito Santo. E-mail: lidio. souza@uol.com.br

3. Doutor em Psicologia,

pesquisador em Psicologia Social no Departamento de Ciências da Educação da Universidade de Bolonha (Itália) E-mail: giannino. melotti@unibo.it

4. Doutor em Psicologia Social, professor Ordinário de Psicologia Social da Faculdade de Psicologia da Universidade de Bolonha (Itália); E-mail: augusto.palmonari@ unibo.it 
tity, which aims to preserve the rural community way of life and guarantees the survival of its sociability through new generations, is discussed.

Keywords: Anchorage, City, Organizing Principles, Rurality, Social Representation.

\section{Introdução}

A construção de uma imagem social que represente o grupo e seus membros em frente à sociedade é um processo complexo que envolve diferentes recursos simbólicos e afetivos. Uma vez que se entra ou nasce em um grupo, é necessário aprender a fazer parte deste e a encontrar ou desenvolver estratégias para nele permanecer (SPELTINI e PALMONARI, 1999). O estudo da sociabilidade camponesa, que se organiza por meio da estrutura social comunitária, favorece a reflexão acerca da dinâmica de pertencimento grupal e de sua relação com os processos de identidade e de representações sociais (MOSCOVICI e DOISE, 1992; SPELTINI e PALMONARI, 1999; TAJFEL, 1982 e 1983; VALA, 1997).

Empregado com diferentes significados nas mais diversas áreas das Ciências Humanas e Sociais, o termo sociabilidade evoca a esfera das relações e interações sociais conjugadas pela força da comunalidade, do convívio e da afetividade. Um conceito de sociabilidade, amplamente difundido no campo sociológico, é o de Georg Simmel, que, de acordo com Veiga (2004), seria uma dimensão característica de um "mundo artificial, composto de indivíduos que não têm outro desejo senão o de criar a pura interação com os demais. Não se entraria na sociabilidade como homens completos, mas como homens despojados de fins, metas e intenções (...) seria a classe mais pura de interação" (p. 10). Como construção histórica e coletiva, a sociabilidade envolve também relações conflitivas e de poder que se manifestam nas diferentes maneiras de pensar, sentir e agir; expressam-se nas diversas dimensões da vida (MOSCOVICl, 1990). A sociabilidade está associada, portanto, aos modos de vida que constituem as comunidades e grupos sociais diversos, pressupondo processos de identificação social.

Nesse sentido, de especial interesse para a Psicologia Social, a ideia de sociabilidade aproxima-se da noção de comunidade assumida neste estudo, pressupondo a existência de atividades integradoras, sentimento de pertença e a formação de laços sociais. Como uma entidade social que se constitui em função de um vínculo particular entre seus membros, sustentada na vontade coletiva, na interação entre as pessoas e em objetivos compartilhados (BONOMO e SOUZA, 2010; DURHAN, 2004; PREZZA e PACILLI, 2002), entendemos a noção de comunidade como equivalente à de grupo social (PALMONARI e ZANI, 2003; SAWAIA, 1996), posto que envolve afetividade, valoração e o reconhecimento de pertença em um espaço comum (TAJFEL, 1982 e 1983). 
As condições que confluem para tecer o modo de vida das pessoas do lugar constituem um sistema de identificação que se fortalece e se mantém especialmente por meio de representações sobre o próprio grupo e pela distinção em relação ao ambiente externo, estranho à sua organização e, por vezes, portador de elementos ameaçadores e perturbadores da ordem e funcionamento grupais. Cabe ao grupo/comunidade, portanto, fornecer aos seus membros os mecanismos apropriados para a manutenção da ordem e do equilíbrio no seu sistema interno e na interação com demais grupos (MOSCOVICl, 2005; SPELTINI e PALMONARI, 1999). O indivíduo, todavia, "é um sujeito ativo (...) que elabora as informações que recebe ordenando-as em categorias e atribuindo seus significados diversos" (PALMONRARI, 1995, p. 13 - tradução nossa), reflexão que reclama o reconhecimento da autonomia relativa do sujeito em frente às relações e ao contexto no qual está inserido. Fala-se em autonomia relativa porque o indivíduo desenvolve-se numa condição grupal que implica o compartilhamento de um sistema simbólico coletivo que, embora constitua constrangimento, possibilita a diversidade de posicionamentos, conflito e negociação entre seus integrantes. É assumindo essa condição dinâmica da vida social que Moscovici e Doise (1992) esclarecem que os indivíduos que compõem determinado grupo precisam "reconhecer a realidade de conflitos de opinião a fim de procurar uma solução iluminada entre as posições antagonistas (...) descobrir que coisa, dentro da aparente diversidade, pode fazer alcançar o consenso" (p. 13 - tradução nossa).

Construídas pelos grupos sociais com a finalidade de "enfrentar a realidade com critérios e linguagem dotados de sentido, compreensíveis não apenas para quem compõe o grupo, mas também, se possível, para os membros dos outros grupos" (PALMONARI, 1995, p. 54 - tradução nossa), as representações sociais guardam profunda relação com os processos de identidade social (BREAKWELL, 1993; DESCHAMPS e MOLINER, 2009; VALA, 1997).

A relação entre as representações e os processos identitários pode ser compreendida com maior clareza quando pensada a partir das relações intra e intergrupais. As hipóteses moscovicianas acerca das funções das representações sociais (MOSCOVICl, 2005) fornecem elementos que fortalecem essa perspectiva dialógica entre os referidos processos: de interesse - o indivíduo ou grupo social procura criar imagens e discursos que respondem às exigências de harmonizar os objetivos contrapostos entre grupos ou dos indivíduos em relação à coletividade; e de equilíbrio - como discursos ideológicos, as representações são utilizadas para resolver tensões psíquicas e emotivas decorrentes de problemas nas interações sociais, visando restaurar o equilíbrio grupo-indivíduo; e de controle - as representações são construídas para serem utilizadas como instrumento de seleção das informações que chegam do ambiente externo, objetivando contro- 
lar a realidade dos indivíduos em relação ao grupo de pertencimento.

Em Dissenso e consenso, Moscovici e Doise (1992) dedicaram-se à reflexão acerca dos processos por meio dos quais os desacordos são vencidos em favor da construção de uma ideia compartilhada, condição gestada não pela conformidade inerte dos indivíduos, mas, sim, pela sua participação ativa. Três seriam as instâncias suficientes para resolver a questão fundamentada na divergência de posições em frente a determinado objeto social: a tradição, a ciência e o consenso. As duas primeiras teriam sucumbido gradativamente em sua autoridade sobre os indivíduos, restando o consenso, cujas ideias de sustentação fundamentam-se na escolha, nos laços de confiança e na identificação de princípios lógicos que justifiquem a opção por uma vida em comum. Moscovici e Doise (1992) esclarecem: "Os atos de decisão, como também os atos de consenso, são, antes de tudo, atos de participação. (...) o seu valor decorre do vínculo que os indivíduos constroem entre eles e da impressão que cada um elabora ao contar com o olhar de todos..." (p. 73 - tradução nossa).

Os autores argumentam que esse trabalho de elaboração de uma interpretação compartilhada transforma as categorias de pensamento individual em categorias de pensamento social, processo que tem na dinâmica grupal sua condição fundadora. Aqui é necessário resgatar a análise de Mazzara (1996) acerca do pertencimento social, posto que esse processo orienta, fortemente, não apenas o modo como as informações sociais são tratadas, mas também como cada um pensa sobre si mesmo e, por conseguinte, como se organizam os fundamentos dinâmicos que constituem e garantem certa permanência à identidade social.

Em torno da questão do consenso, desenvolveram-se duas das principais abordagens da teoria das representações sociais (PALMONARI, 2009; RATEAU, 2004), a partir de perspectivas opostas: a teoria do núcleo central (ABRIC, 2003) e a teoria dos princípios organizadores das representações sociais (DOISE, 1992, 2002a e 2002b; DOISE, CLÉMENCE e LORENZI-CIOLDI, 1995), ou o paradigma das "três fases", como também é conhecida (PALMONARI, 2009). Enquanto a primeira focaliza a análise sobre os elementos compartilhados em relação a determinado objeto, a segunda apoia-se na investigação dos princípios sobre os quais os elementos diferenciam-se. De acordo com Rateau (2004), enquanto o pressuposto subjacente à teoria consensual consiste na significação constitutiva do objeto, na teoria não consensual (dos princípios organizadores das representações) consiste na avaliação do objeto.

De acordo com Doise e seus colaboradores (1995), as representações podem ser definidas "como princípios geradores de tomadas de posição que estão vinculadas a inserções específicas em um conjunto de relações sociais capazes de organizar os processos simbólicos que intervêm nestas relações" (p. 187 - tradução 
nossa). A noção de princípios organizadores insere a valorização das diferenças interindividuais no campo de estudos das representações sociais, possibilitando a sua apreensão e análise como fenômeno dinâmico e complexo. O quadro teórico-metodológico dessa abordagem fundamenta-se no desenvolvimento do estudo das representações por meio de três fases, a saber: composição do campo representacional (campo semântico associado aos objetos), identificação dos princípios organizadores das diferenças individuais (variabilidade do campo) e análise da ancoragem dos princípios organizadores das representações (DOISE, 1992; DOISE, CLÉMENCE e LORENZI-CIOLDI, 1995).

No que concerne à análise dos processos de ancoragem, esta foi proposta em três modalidades, conforme esquematização teórico-conceitual fornecida por Doise (1992): a ancoragem psicológica - modulações individuais do campo representacional; a ancoragem social - crenças, opiniões e experiências comuns compartilhadas pelos membros de um dado grupo, que originam representações com uma dinâmica semelhante; e, por fim, a ancoragem psicossocial - o modo como os indivíduos estão simbolicamente ligados às relações sociais e aos diferentes posicionamentos e categorias próprios de determinado campo social. É importante ressaltar que, junto com o processo de objetivação, a ancoragem consiste em um dos mecanismos que conferem às representações sociais a eficácia de tornar familiar o estranho (MOSCOVICl, 2005), permitindo a acomodação de algo considerado ameaçador ao nosso sistema de categorias (GALLI, 2006).

De acordo com Clémence (2003), a análise do campo representacional deve considerar a estratificação das posições de pertencimento social em conformidade com as categorias hierárquicas produzidas em meio ao campo de força dominante-minoritário, fortalecendo o argumento apresentado por Doise (1992; 2002a; 2002b) de que as "produções culturais e ideológicas, características de uma sociedade ou de certos grupos, não somente dão significação aos comportamentos dos indivíduos, como também criam ou dão suporte às diferenciações sociais em nome de princípios gerais" (DOISE, 2002b, p. 28).

A diversidade de significados que constituem e sustentam o pensamento social é, portanto, orquestrada pelos princípios que organizam as diferenças individuais, os quais indicam que "a sociedade é um sistema de relações caracterizadas pela pluralidade de alternativas, onde cada indivíduo tem uma inserção específica no campo social" (PEREIRA, 2004, p. 40), sociedade que também pode ser caracterizada por um "(...) permanente movimento de "entrar" e "sair", de separar e unir, quer seja relacionado ao indivíduo nas suas múltiplas pertenças aos grupos e nos seus status e papéis sociais, quer seja aos grupos sociais (...)" (SPELTINI e PALMONARI, 1999, p. 49 - tradução nossa). 
No Brasil, poucas pesquisas sobre representações sociais têm sido desenvolvidas a partir do paradigma das três fases (PEREIRA, 2004; ALMEIDA, 2009). Entre as ainda escassas investigações que podem ser encontradas na literatura nacional, apresentam-se o estudo sobre preconceito contra homossexuais, a partir da análise da ancoragem social realizado por Lacerda, Pereira e Camino (2002), a investigação sobre os princípios organizadores do envolvimento nos Direitos Humanos e ideologia política conduzida por Pereira e Camino (2003) e o trabaIho sobre as representações sociais de envelhecimento realizado por Wachelke et al. (2008), no qual também os princípios organizadores das representações foram estudados.

A presente investigação orientou-se pela teoria não consensual das representações sociais, cuja contribuição à análise dos objetos de representação abordados decorre da possibilidade de apreensão dos componentes simbolicamente relevantes do grupo para a construção da identidade social, segundo as diferentes inserções individuais na comunidade rural (BONOMO e SOUZA, 2010).

Dirigindo o foco de análise para os processos que regulam a elaboração da imagem social de um grupo que se estrutura a partir da categoria social camponesa, indicamos a seguir os objetivos que orientaram a investigação dos objetos de representação, tendo em vista a organização social do modo de vida dos participantes a partir da comunidade: (a) conhecer o campo semântico associado aos objetos de representação: rural e cidade; (b) investigar os princípios organizadores das tomadas de posição individuais em relação ao conteúdo compartilhado das representações sociais abordadas; (c) analisar os processos de ancoragem psicológica, social e psicossocial das representações sociais em questão; e, finalmente, (d) articular os resultados do campo representacional de rural e cidade, a fim de discutir as funções da elaboração do referido campo para o grupo rural investigado.

\section{Estratégias metodológicas}

\section{Participantes e procedimento de coleta dos dados}

Participaram do estudo 200 integrantes de quatro gerações de uma comunidade rural localizada na região norte do Estado do Espírito Santo, com idades que variavam entre 7 e 81 anos, conforme detalhamento a seguir: quarta geração entre 7 e 12 anos; terceira entre 15 e 25 anos; segunda entre 35 e 45 anos; e primeira geração com 60 anos ou mais. A amostra equivale a $35 \%$ do total de membros da comunidade, cujas características mais relevantes encontram-se detalhadas no estudo realizado por Bonomo e Souza (2010). 
Os dados foram coletados na própria comunidade rural, por meio de entrevistas individuais, em locais sugeridos pelos participantes, respeitando a sua disponibilidade. Todas as entrevistas foram precedidas do esclarecimento dos objetivos do trabalho, bem como da leitura e assinatura do Termo de Consentimento Livre e Esclarecido para participação em pesquisas.

\section{Instrumento e tratamento dos dados}

O instrumento utilizado para a coleta das informações continha quatro núcleos de informação: (1) dados sociodemográficos referentes a sexo, idade, grupo geracional e se o participante já havia vivido em áreas urbanas; (2) conjunto de informações sobre experiência de preconceito, por ser reconhecido como pessoa do meio rural, expectativa ou não de viver na cidade, e se recomendaria viver na cidade; (3) indicação de pelo menos três valores vinculados ao rural; e (4) evocações livres associadas aos objetos de representação rural e cidade.

Os dados provenientes dos dois primeiros tópicos foram sistematizados por meio de procedimentos da estatística descritiva. Em relação aos corpora de dados constituídos pelos valores associados ao rural (tópico 3) e pelas evocações livres (tópico 4), primeiramente se procedeu a categorização dos elementos, utilizando-se o critério semântico para agrupamento/distinção e, posteriormente, submeteu-se as categorias de cada conjunto de dados aos procedimentos do software SPAD-T (LEBART, BECUE e HAEUSLER, 1994), o que tornou possível identificar os clusters referentes aos valores associados ao rural, às representações de rural e às representações de cidade.

O arranjo desse conjunto de dados forneceu as bases empíricas para a definição das variáveis para o processo de análise das ancoragens das representações sociais dos objetos investigados. É importante ressaltar que a descrição e análise dos resultados têm como referência o posicionamento dos indivíduos no campo representacional, a partir de suas inserções grupais, conforme método de investigação proposto por Doise, Clémence e Lorenzi-Cioldi (1995).

\section{Resultados}

\section{Conteúdo compartilhado das representações sociais de rural e cidade}

O corpus de dados referente ao rural foi composto por 984 palavras, tendo sido consideradas pela análise do software SPAD-T 89.63\% desse total (882 termos), com média de evocação de 4.9 palavras. Para o corpus relativo ao objeto cidade, foram considerados 803 elementos (87.66\%) de um total de 916 termos, com evocação média de 4.6 palavras por indivíduo. O conjunto total de elementos 
constituintes do campo semântico de cada objeto (a partir do corte referenciado por $f \geq 07$ ) apresentou o mesmo número de categorias diferentes ( $n=47$ ), denotando um investimento equilibrado no sistema de significação relativo aos objetos de representação, conforme disposição dos elementos na Tabela 1, a seguir.

Tabela 1 - Elementos característicos das representações de cidade e rural

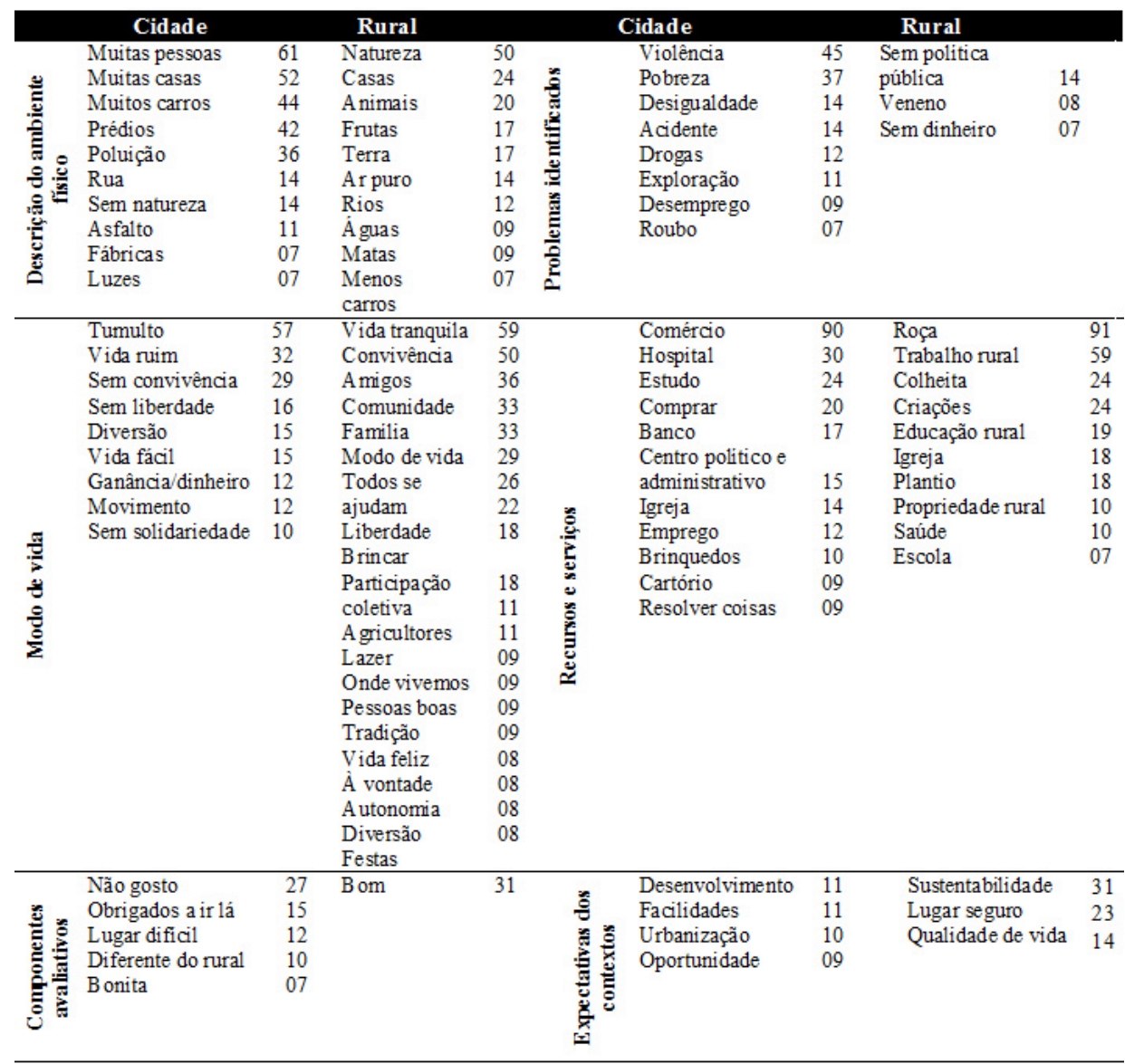

As seis categorias elaboradas, descritas a seguir, fornecem um panorama dos elementos que constituem o conteúdo compartilhado das representações sociais de rural e cidade, facilitando sua exploração inicial: 1) Descrição do ambiente físico: apresenta elementos relacionados à organização espacial dos territórios (rua/asfalto/poluição vs. terra/rio/ar puro); 2) Problemas identificados: engloba os pontos críticos e as dificuldades enfrentadas em cada contexto (a cidade como violenta e pobre, e o campo associado à ausência de política pública e ao uso de veneno); 3) Modo de vida: integra significados que, em sua 
maioria, colocam em oposição as sociabilidades rural e citadina (convivência/ liberdade/vida feliz vs. sem convivência/sem liberdade/vida ruim); 4) Recursos e serviços: refere-se à infraestrutura de cada território, como comércio, banco ou cartório para a cidade (recursos que são utilizados também pelo grupo rural) e propriedade rural, educação rural e criações para o campo, os quais constituem elementos basilares à sobrevivência das pessoas do lugar; 5) Componentes avaliativos: refere-se ao posicionamento avaliativo dos participantes em relação aos dois territórios. Ao rural foi associado um único elemento, este com conotação positiva (bom), e à cidade foram relacionados significados positivos (bonita) e também negativos (não gosto); 6) Expectativas dos contextos: diz respeito a elementos que poderíamos considerar "as promessas" de cada território à população (cidade: desenvolvimento, facilidades; rural: sustentabilidade, lugar seguro). Os significados subjacentes aos elementos referentes à cidade compõem uma imagem que sugere sua perspectiva desenvolvimentista, enquanto o sentido associado ao rural parece transmitir a ideia de um modo de vida autossustentável.

Os elementos que constituíram o campo representacional vinculado aos objetos em análise, rural e cidade, foram agrupados em categorias semânticas gerais, a fim de fornecer uma visão mais ampla e integral dos significados que concorrem para a elaboração dos referidos campos. Embora possam apresentar contraposições no que se refere à polaridade do conteúdo que representam - evidência que já indica a possível tomada de posição dos participantes a partir do pertencimento ao grupo rural (BROWN, 1997; DOISE, 2002a, 2002b; TAJFEL, 1982, 1983) -, as categorias elaboradas visam retratar os aspectos comuns em termos semânticos, tendo como referência a comparação entre os dois campos.

\section{Análise dos processos de ancoragem}

\section{Definição das variáveis de acordo com cada modalidade de ancoragem}

Tendo como objetivo evidenciar as diferenças individuais em relação aos objetos de representação rural e cidade, foi realizada a análise de correspondência a partir do procedimento ASPAR, do software SPAD-T (LEBART, BECUE e HAEUSLER, 1994). Essa análise permite individualizar os princípios sobre os quais se organizam as tomadas de posição dos participantes, por meio da análise da oposição entre os polos de cada fator (DOISE, 2002a). A formação de clusters, por sua vez, fornece as posições individuais dos participantes em frente às representações sociais, de acordo com o campo semântico que as constitui (BERTI, PIVETTI e MELOTTI, 2008). Para cada objeto de representação, foi possível identificar três clusters de sujeitos, segundo os elementos associados aos termos indutores rural e cidade. Nas Tabelas 2 e 3 são apresentados, respectivamente, os clusters 
concernentes às representações de rural e cidade, acompanhados das categorias significativamente mais frequentes e menos frequentes, bases empíricas para a investigação da ancoragem psicológica. Para demonstrar como as diferentes pertenças sociais modulam as representações sociais de rural e cidade, analisamos o posicionamento dos indivíduos nos fatores formados por meio da projeção das variáveis sexo ( $n f=100$ e $n m=100)$, geração ( $n G 1=50, n G 2=50$, $n G 3=50$ e $n G 4=50)$ e se o participante viveu na cidade $(n=25)$ ou não $(n=175)$, análise que possibilita discutir a ancoragem social das representações de rural e cidade.

O quadro que permite a análise do campo semântico dos objetos de representação social pode ser sintetizado da seguinte forma: a ancoragem psicológica será evidenciada por meio da análise de correspondência e da formação de clusters compostos por sujeitos, segundo o conjunto de elementos das representações sociais de cada objeto; a ancoragem social por meio da projeção, nos fatores analisados, das variáveis suplementares sexo, geração e se viveu na cidade; e, por fim, por meio dos valores associados ao rural, da experiência de preconceito, da expectativa ou não de vida na cidade (para os participantes que sempre viveram no meio rural) e se recomenda a vida na cidade (para os migrados que retornaram à comunidade rural) será analisada a ancoragem psicossocial.

Para determinar o nível de aceitação dos elementos mais significativos para a formação dos fatores na Análise Fatorial de Correspondência, é utilizada a regra c.a. $\geq 100 / n$ das categorias/elementos, sendo c.a. = contributo absoluto. Considerando que cada campo semântico vinculado aos objetos de representação foi constituído por 47 categorias, o valor considerado para destacar os elementos significativos à formação dos fatores foi de 2,12. Para estabelecer o nível de aceitação das variáveis, usa-se o critério do V-test $\geq|2|$ (BERTI, PIVETTI e MELOTTI, 2008).

Apresentaremos, a seguir, os resultados relacionados à análise dos processos de ancoragens psicológica e social relativos ao rural e, na sequência, o conjunto de dados referentes às representações sociais de cidade.

Representações sociais de rural

\section{1) Ancoragem psicológica}

Na Figura 1, é apresentado o plano fatorial proveniente do cruzamento dos Fatores 1 e 2, selecionados para a apresentação dos resultados referentes ao campo representacional de rural. 
Figura 1: Análise de correspondência - plano fatorial referente ao campo representacional de rural

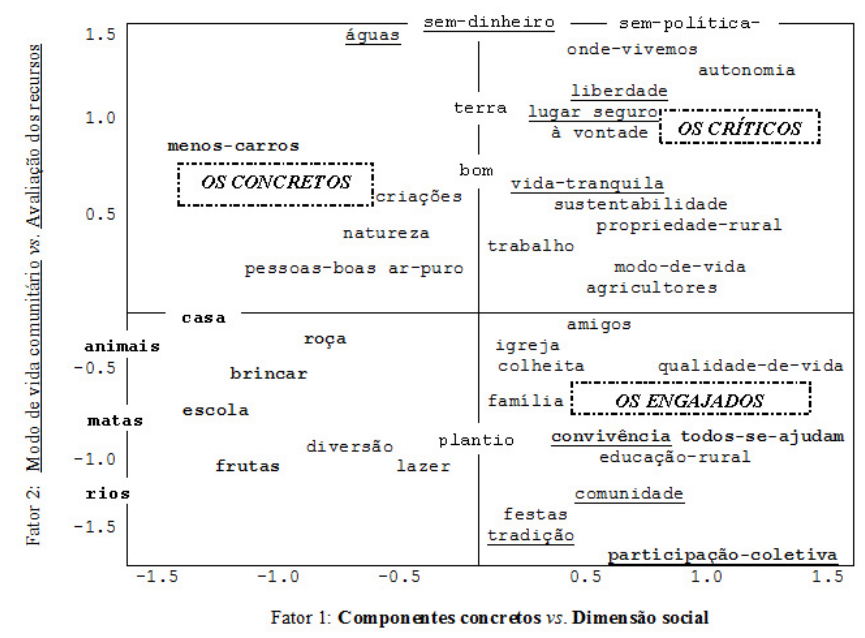

O Fator 1 Componentes concretos vs. Dimensão social (5.8\% de inércia empregada) evidencia a contraposição entre uma imagem objetiva do rural e a dimensão social que organiza o modo de vida na comunidade. O polo negativo (Componentes concretos) apresenta o tema natureza (entre parênteses é fornecido o valor de c.a. - contributo absoluto), com os animais (11.2), as matas (8.5), os rios (7.9) e as frutas (7.8), espaço menos movimentado, com menos carros (3.4), convidativo a atividades como o brincar (4.5), especialmente para as novas gerações. Contribuem ainda para a elaboração da imagem do rural, componentes figurativos como casas (10.1), escola (3.0) e roça (5.8), os quais destacam a apropriação humana do espaço.

Em oposição ao polo concreto, posiciona-se a Dimensão social. Projetam-se sobre a referida dimensão elementos que retratam o rural a partir da convivência (5.2) entre as pessoas do lugar e a participação coletiva (3.4) nas atividades desenvolvidas, formas de mobilização social nas quais todos se ajudam (3.1) e em que a vivência de uma sociabilidade compartilhada é fortalecida.

O segundo fator, Modo de vida comunitário vs. Avaliação dos recursos (4.38\% de inércia empregada) permite ampliar a análise sobre a sociabilidade camponesa. No polo negativo desse fator, Modo de vida comunitário, pode-se identificar 
5. Listagem das categorias significativamente mais frequentes e menos frequentes segundo critério V-test $\geq|2|$ claramente o modo de vida rural. Em comparação com o eixo anterior, nota-se a inclusão dos elementos comunidade (2.7) e tradição (3.0), o que fortalece os significados convivência (2.2) e participação coletiva (8.9) e indica a importância do modelo comunitário para a estruturação e organização do grupo.

No polo positivo, Avaliação dos recursos pode-se identificar os recursos naturais, como águas (5.3) e terra (2.7), e os recursos sociais, os quais organizam o modo de vida do lugar, com autonomia (2.2) e liberdade (5.0), tornando o território rural um lugar seguro (4.5) e de vida tranquila (2.7). O elemento onde vivemos (2.6) indica a relevância dos significados associados ao objeto rural para a identidade social do grupo. Contrastam, todavia, com essa imagem harmônica e autossustentável os elementos sem política rural (3.1) e sem dinheiro (6.0), incluindo no corpo de significação do rural as dificuldades concretas de sobrevivência no campo e também a crítica à hierarquia social, política e econômica que confere à cidade maior poder que ao campo.

Associados às representações de rural, foram identificados três clusters compostos por participantes que, em função dos significados mais característicos que os constituem, foram denominados de Os engajados, Os críticos e Os concretos, conforme detalhamento na Tabela 2.

Tabela 2 - Composição dos clusters: representação social de rural ${ }^{5}$

\begin{tabular}{|c|c|c|c|c|c|}
\hline \multicolumn{2}{|c|}{$\begin{array}{c}\text { Cluster } 1 \\
\text { Os engajados-rural }\end{array}$} & \multicolumn{2}{|c|}{$\begin{array}{c}\text { Cluster } 2 \\
\text { Os criticos-rural }\end{array}$} & \multicolumn{2}{|c|}{$\begin{array}{c}\text { Cluster } 3 \\
\text { Os concretos-rural }\end{array}$} \\
\hline $\begin{array}{l}\text { Categorias de } \\
\text { elementos mais } \\
\text { frequentes }\end{array}$ & $\begin{array}{c}\text { Categorias de } \\
\text { elementos } \\
\text { menos } \\
\text { frequentes }\end{array}$ & $\begin{array}{l}\text { Categorias de } \\
\text { elementos mais } \\
\text { frequentes }\end{array}$ & $\begin{array}{l}\text { Categorias de } \\
\text { elementos } \\
\text { menos } \\
\text { frequentes }\end{array}$ & $\begin{array}{c}\text { Categorias de } \\
\text { elementos } \\
\text { mais } \\
\text { frequentes }\end{array}$ & $\begin{array}{c}\text { Categorias de } \\
\text { elementos } \\
\text { menos } \\
\text { frequentes }\end{array}$ \\
\hline Convivência & Brincar & Sem politica rural & & Frutas & Liberdade \\
\hline Modo de vida & Menos carros & Sem dinheiro & & Animais & Vida tranquila \\
\hline Amigos & Sem dinheiro & & & Casas & Trabalho \\
\hline Sustentabilidade & Escola & & & Rios & Modo de vida \\
\hline Vida tranquila & Matas & & & Matas & Amigos \\
\hline Liberdade & Rios & & & Brincar & Convivência \\
\hline Participação & An imais & & & Escola & \\
\hline coletiva & Casas & & & Menos carros & \\
\hline & Sem política & & & Roça & \\
\hline & rural & & & & \\
\hline & Frutas & & & & \\
\hline
\end{tabular}

O cluster 1 agrupa 143 indivíduos e foi composto por 647 termos analisados que correspondem a 41 palavras distintas. Esse grupo, chamado de Os engajados-rural, congrega significados relativos aos aspectos da sociabilidade da comunidade e localiza-se de forma significativa nos polos Dimensão social (V-test = 8,5 - Fator 1) e Modo de vida comunitário (V-test = -3,7 - Fator 2) e está menos envolvido no posicionamento crítico em frente ao contexto rural e com sua face mais objetiva/concreta. O cluster 2, Os críticos-rural, é formado por 15 partici- 
pantes e foi incluído no polo Avaliação dos recursos (V-test $=6,4$ - Fator 2). 0 seu conteúdo baseia-se em 55 termos analisados, agrupados em 26 elementos diferentes, e apresenta exclusivamente a crítica em relação à ausência de política pública para o meio rural e à pobreza decorrente do agravamento das dificuldades relacionadas à produção e comercialização dos produtos agrícolas. Finalmente, o cluster 3 é composto por 42 indivíduos - Os concretos-rural - que foram projetados no polo Componentes concretos (V-test $=-11,5-$ Fator 1 ). Os significados que o caracterizam decorrem de 180 termos analisados (33 palavras distintas) e enfatizam os aspectos concretos.

\section{2) Ancoragem social}

Entre as variáveis selecionadas para a análise da ancoragem social, apenas geração e ter vivido na cidade concorrem para a elaboração do campo representacional de rural.

Os significados de rural organizados no fator Componentes concretos (Fator 1) são elaborados principalmente pelos membros da quarta geração ( $V$-test = $-21,4$, coord1: $-1,3$ ) e pelos que não viveram na cidade ( $V$-test $=-6,2$, coord1: -.08). Por possuírem menos recursos para a comparação entre campo-cidade, elaboram uma imagem do objeto que pode ser considerada mais simplificada.

O tipo de sociabilidade ocupa um lugar central no campo representacional elaborado, posto que organiza os polos positivo do Fator 1 (Dimensão social) e negativo do Fator 2 (Modo de vida comunitário). No segundo polo do Fator 1, estão a primeira ( $V$-test $=7.1$, coord1: .41), a segunda ( -test $=9.3$, coord1: .53) e a terceira gerações ( $V$-test $=4.4$, coord1: .26), inclusive os indivíduos que já viveram em áreas urbanas (V-test $=6.2$, coord1: .56), o que apoia a interpretação de que as experiências na cidade contribuem para a construção de uma imagem mais elaborada do rural, uma vez que favorecem processos de comparação entre as duas realidades.

No Eixo 2, Modo de vida comunitário vs. Avaliação dos recursos, projeta-se apenas a variável geração, cujos significados sugerem a preocupação dos participantes com a continuidade do modo de vida na comunidade. Verifica-se que as novas gerações associam-se aos significados que compõem o Modo de vida comunitário. A terceira ( $\mathrm{V}$-test $=-7.4$, coord2: -.27 ) e a quarta gerações ( $\mathrm{V}$-test $=-2.0$, coord2: -.21 ) colocam-se significativamente nesse polo. Já a primeira ( $\mathrm{V}$ -test $=2.7$, coord2: .16) e a segunda gerações ( $V$-test $=2.0$, coord2: .11), mais preocupadas com o futuro da comunidade e de seus filhos, são responsáveis pela dimensão Avaliação dos recursos. 
Representações sociais de cidade

\section{1) Ancoragem psicológica}

O plano fatorial resultante da análise de correspondência referente ao campo representacional de cidade é apresentado na Figura 2, por meio da projeção dos Fatores 1 e 2. O campo representacional vinculado ao objeto cidade é apresentado pelo cruzamento dos Fatores 1 Centro dos recursos vs. Modo de vida ruim (5.71\% de inércia empregada) e 2 Dimensão instrumental vs. Componentes concretos ( $4.97 \%$ de inércia empregada).

Figura 2 - Análise de correspondência - plano fatorial referente ao campo representacional de cidade

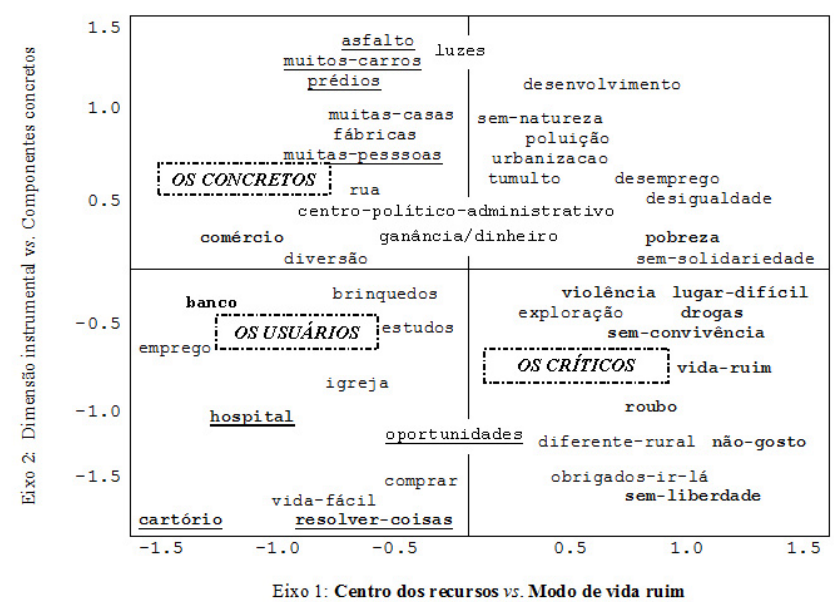

O polo negativo do primeiro fator (Centro dos recursos) contém significados que organizam a representação de cidade a partir dos serviços disponíveis no território (entre parênteses, é fornecido o valor de c.a. - contributo absoluto), como banco (3.0), cartório (4.6), comércio (13.1), hospital (5.6) e um lugar aonde se vai para resolver coisas (3.3). A Dimensão instrumental da cidade (Fator 2) também enfatiza os recursos, cartório (5.5) e hospital (2.5), o que reforça a ideia de cidade como lugar para resolver coisas (26.7) ou comprar o que se precisa (9.4), sendo percebida pelos participantes como vida fácil (15.7) e oportunidades (3.3).

Ainda no primeiro eixo, no polo oposto, encontra-se a ideia de cidade como um contexto que congrega diversos problemas, como pobreza (3.5), violência (5.6), drogas (3.9) e acidentes (7.4), além da falta de convivência (4.5) e de ausência de liberdade (4.0). A avaliação dos participantes, manifestada em elementos como não gosto (6.1), lugar difícil (4.2) e vida ruim (6.0), expressa a ausência de 
identificação dos integrantes do grupo rural com o modo de vida urbano.

Finalmente, o polo positivo do Fator 2 (Componentes concretos) refere-se à dimensão figurativa do espaço citadino, composta por asfalto (2.2), prédios (4.9), muitos carros (5.9), muitas casas (4.6) e muitas pessoas (2.9).

O agrupamento de categorias de indivíduos em frente ao objeto de representação resultou na identificação de três clusters de sujeitos associados a significados distintos de representações sociais de cidade. Na Tabela 3, são fornecidas as informações relativas aos grupos formados e os elementos mais e menos característicos.

Tabela 3 - Composição dos clusters: representação social de cidade ${ }^{6}$

\begin{tabular}{|c|c|c|c|c|c|}
\hline \multicolumn{2}{|c|}{$\begin{array}{c}\text { Cluster } 1 \\
\text { Os criticos-cidade }\end{array}$} & \multicolumn{2}{|c|}{$\begin{array}{c}\text { Cluster } 2 \\
\text { Os usuários-cidade }\end{array}$} & \multicolumn{2}{|c|}{$\begin{array}{c}\text { Cluster } 3 \\
\text { Os concretos-cidade }\end{array}$} \\
\hline $\begin{array}{l}\text { Categorias de } \\
\text { elementos mais } \\
\text { frequentes }\end{array}$ & $\begin{array}{l}\text { Categorias de } \\
\text { elementos } \\
\text { menos } \\
\text { frequentes }\end{array}$ & $\begin{array}{l}\text { Categorias de } \\
\text { el ementos mais } \\
\text { frequentes }\end{array}$ & $\begin{array}{c}\text { Categorias } \\
\text { de } \\
\text { elementos } \\
\text { menos } \\
\text { frequentes }\end{array}$ & $\begin{array}{l}\text { Categorias de } \\
\text { elementos } \\
\text { mais } \\
\text { frequentes }\end{array}$ & $\begin{array}{l}\text { Categorias de } \\
\text { elementos menos } \\
\text { frequentes }\end{array}$ \\
\hline Não gosto & Asfal to & Vida fácil & & Comércio & Vida boa \\
\hline Violência & Vida fácil & Resolver coisas & & Muitos carros & Pobreza \\
\hline Sem convivência & Banco & Cartório & & Prédios & Lugar dificil \\
\hline Vida ruim & Hospital & Oportunidades & & Muitas pessoas & Drogas \\
\hline Acidente & Diversão & Comprar & & Muitas casas & Acidente \\
\hline Lugar dificil & Muitas casas & Hospital & & Asfalto & Sem convivência \\
\hline Drogas & Muitas pessoas & & & Diversão & Vida ruim \\
\hline Pobreza & Prédios & & & Banco & Sem liberdade \\
\hline Sem liberdade & Muitos carros & & & Movimento & Violência \\
\hline Desigualdade & Comércio & & & & Não gosto \\
\hline
\end{tabular}

Os significados do primeiro cluster, formado por 76 indivíduos, são provenientes de 301 termos analisados (41 distintos); espelham a avaliação negativa do modo de vida urbano, posição que resultou no nome de Os críticos. Em função do conteúdo que o constitui, esse cluster localiza-se no polo Modo de vida ruim (V-test $=11.7$ - Fator 1 ). O cluster 2 , composto por 16 sujeitos foi denominado Os usuários, por retratar a cidade a partir da imagem de Centro dos recursos (V-test =-2.8 - Fator 1 ) e de sua Dimensão instrumental (V-test =-10.2 - Fator 2). Integram o conjunto de elementos associados a esse grupo 60 termos analisados, distribuídos em 23 categorias diferentes. No cluster 3, encontra-se o agrupamento mais numeroso, composto por 108 participantes. O conjunto de dados foi constituído por 442 elementos do total de termos analisados pelo programa SPAD-T, com 40 categorias semânticas distintas. Os integrantes do agrupamento foram chamados de Os concretos, por demonstrarem maior preocupação com os Componentes concretos da cidade (V-test $=7.2$ - Fator 2 ) e menos interessados com o seu modo de vida. 
7. Lista de 33 palavras mais frequentes $(f \geq 6)$

\section{2) Ancoragem social}

A cidade como o Centro dos recursos foi enfatizada pela quarta geração (V-test $=-7.2$, coord1: -.46 ) e pelos que nunca viveram em território urbano ( $\mathrm{V}$-test $=$ -4.3, coord1: -.06), imagem que se contrapõe à avaliação negativa do modo de vida urbano (polo positivo do Fator 1), a qual é destacada pela primeira (V-test $=3.6$, coord1: .22) e segunda gerações (V-test $=4.6$, coord1: .29) e pelos que já viveram na cidade ( $\mathrm{V}$-test $=4.3$, coord1:.41).

No Fator 2, sobre o polo Dimensão instrumental, projetam-se a primeira geração (V-test $=-13.4$, coord2:-.83) e os integrantes do grupo rural que já viveram na cidade ( $V$-test $=-3.1$, coord2:-.29). A terceira ( -test $=5.2$, coord2: $: 30)$ e a quarta gerações ( $V$-test $=9.1$, coord2:.58), e também os que não viveram na cidade (V-test $=3.1$, coord2:.04), elaboraram uma imagem mais concreta e objetiva (Componentes concretos) da cidade.

Ancoragem psicossocial das representações sociais de rural e de cidade

Para a análise da ancoragem psicossocial, consideraram-se as seguintes variáveis: se já pensou em viver na cidade (para os participantes que sempre viveram no meio rural) (nsim=39 e nnão=136); se recomenda a vida na cidade (para os participantes que já viveram na cidade) ( $n$ sim= 04 e nnão=21); se já sofreu preconceito por ser identificado como pessoa rural (nsim=66 e nnão=134) e clusters referentes aos valores sociais associados ao rural (Tabela 5).

No que se refere especificamente à formação dos clusters de sujeitos a partir dos valores associados ao rural, foi produzido um total de 768 termos, com 52 categorias distintas. Como limite de corte para redução do banco de dados, foi adotada a frequência $\geq 6$. Os 33 elementos que compuseram o corpus de dados referentes aos valores associados ao rural são apresentados na Tabela 4, a seguir.

Tabela 4 - Frequência absoluta dos valores associados a pessoas rurais ${ }^{7}$

\begin{tabular}{llllll}
\hline Termo evocado & Freq. & Termo evocado & Freq. & Termo evocado & Freq. \\
\hline Respeito & 93 & Convivência & 25 & Si mesmo & 08 \\
Alteridade & 61 & Bondade & 23 & Vontade de progredir & 07 \\
Educação & 54 & Estudo & 21 & Alegria & 07 \\
Honestidade & 49 & Paz & 21 & Companheirismo & 07 \\
Trabalho & 46 & Simplicidade & 18 & Participação & 07 \\
Pessoa direita & 44 & Tradição da roça & 12 & Ser verdadeiro & 07 \\
Solidariedade & 38 & Humildade & 10 & Honrar nome palavra & 06 \\
Amizade & 32 & Terra & 09 & Se comportar bem & 06 \\
Familia & 29 & Partilha & 09 & Sinceridade & 06 \\
Religião & 29 & Responsabilidade & 09 & & \\
Vida em comum & 28 & Dignidade & 08 & & \\
\hline
\end{tabular}


Com a finalidade de conhecer as diferentes tomadas de posição em relação aos valores relacionados ao rural, por meio do software SPAD-T, procurou-se identificar a formação de clusters de sujeitos em frente ao conteúdo valorativo, conforme apresentado na Tabela 5.

Tabela 5 - Composição de cluster - categorias de valores utilizadas (mais frequentes e menos frequentes) associadas ao rural $^{8}$

\begin{tabular}{|c|c|c|c|c|c|}
\hline \multicolumn{2}{|c|}{$\begin{array}{c}\text { Chuster } 1 \\
\text { Valores comunitários-endogrupais } \\
99 \text { individuos }\end{array}$} & \multicolumn{2}{|c|}{$\begin{array}{c}\text { Cluster } 2 \\
\text { Valores intergrupais } \\
48 \text { individuos }\end{array}$} & \multicolumn{2}{|c|}{$\begin{array}{c}\text { Cluster } 3 \\
\text { Valores individuais } \\
53 \text { individuos }\end{array}$} \\
\hline $\begin{array}{l}\text { Categorias de } \\
\text { elementos mais } \\
\text { frequentes }\end{array}$ & $\begin{array}{l}\text { Categorias de } \\
\text { elementos menos } \\
\text { frequentes }\end{array}$ & $\begin{array}{l}\text { Categorias de } \\
\text { elementos mais } \\
\text { frequentes }\end{array}$ & $\begin{array}{l}\text { Categorias de } \\
\text { elementos menos } \\
\text { frequentes }\end{array}$ & $\begin{array}{l}\text { Categorias de } \\
\text { elementos mais } \\
\text { frequentes }\end{array}$ & $\begin{array}{l}\text { Categorias de } \\
\text { elementos } \\
\text { menos } \\
\text { frequentes }\end{array}$ \\
\hline $\begin{array}{l}\text { Vida em comum } \\
\text { Convivência } \\
\text { Amizade } \\
\text { Familia } \\
\text { Responsabilidades } \\
\text { Relação com a terra } \\
\text { Religião } \\
\text { Vontade de } \\
\text { progredir }\end{array}$ & $\begin{array}{l}\text { Alteridade } \\
\text { Se comporta bem } \\
\text { Sinceridade } \\
\text { Honrar } \\
\text { nome/palavra } \\
\text { Humildade } \\
\text { Dignidade } \\
\text { Simplicidade } \\
\text { Honestidade } \\
\text { Bondade }\end{array}$ & $\begin{array}{l}\text { Bondade } \\
\text { Alteridade } \\
\text { Paz } \\
\text { Se comporta bem }\end{array}$ & $\begin{array}{l}\text { Amizade } \\
\text { Vida em comum } \\
\text { Honestidade }\end{array}$ & $\begin{array}{l}\text { Honestidade } \\
\text { Simplicidade } \\
\text { Dignidade } \\
\text { Honrar } \\
\text { nome/palavra } \\
\text { Sinceridade } \\
\text { Humildade } \\
\text { Ser verdadeiro }\end{array}$ & $\begin{array}{l}\text { Estudo } \\
\text { Educação } \\
\text { Alteridade } \\
\text { Vida em comum } \\
\text { Paz } \\
\text { Bondade } \\
\text { Convivência }\end{array}$ \\
\hline
\end{tabular}

A análise sugere a distribuição dos participantes em três categorias, as quais representam: valores que podem ser considerados mais individuais (cluster 3 ), na medida em que expressam a prática de princípios relevantes ao grupo pelos seus integrantes; valores comunitários (cluster 1), que retratam as relações endogrupais, suas unidades internas de organização e a caracterização do modo de vida do grupo rural; e, finalmente, os valores intergrupais (cluster 2), compostos por elementos que indicam a comunidade como acolhedora e solidária no confronto com outros grupos.

\section{Ancoragem psicossocial de rural}

Sobre o polo negativo do Fator 1, Componentes concretos, estão os indivíduos que nunca pensaram em viver na cidade (V-test $=-7.1$, coord1: -.16$)$, os que não sofreram preconceito (V-test $=-7.3$, coord1: -.17 ) e os sujeitos que compõem o cluster 2 (valores intergrupais) (V-test $=-10.4$, coord1: -.64 ). No polo oposto, Dimensão social, estão os participantes que viveram na cidade e os que não recomendam o modo de vida desse contexto ( $V$-test $=5.4$, coord1: .55), os que nunca viveram na cidade, mas já pensaram na possibilidade de emigrar ( $V$-test = 3.1, coord1: .22), os que sofreram preconceito por serem identificados como pessoas rurais (V-test $=7.3$, coord1: .35 ), os indivíduos com valores comunitários-endogrupais (cluster 1 ) (V-test $=5.4$, coord1: .18) e ainda os com valores individuais (cluster 3) (V-test $=-3.9$, coord1: .22).

A comparação entre os polos desse primeiro eixo ratifica a análise realizada na seção referente à ancoragem social: os indivíduos que vivenciaram situações
8. Listagem das categorias significativamente mais $\mathrm{e}$ menos frequentes, segundo critério $V$ -test $\geq|2|$ 
que favoreceram a avaliação entre os contextos campo-cidade, elaboram uma representação mais complexa do rural quando comparada com a apenas descritiva do território, indicativa de uma comparação social campo-cidade mais fraca.

No segundo fator, Modo de vida comunitário vs. Avaliação dos recursos, as variáveis ter sofrido preconceito e se recomenda a vida na cidade (para os que já moraram em áreas urbanas) não se projetam significativamente sobre esse eixo. A tomada de posição dos indivíduos no confronto com os significados que articulam a imagem do rural-comunitário (polo negativo) é favorecida por integrantes que nunca pensaram em viver na cidade (V-test $=-3.8$, coord2: -.08 ) e pelos sujeitos incluídos no cluster 1 (Valores comunitários-endogrupais) (V-test $=-2.5$, coord2: -.08 ). As variáveis associadas a esse polo fornecem evidências da composição de uma imagem do rural que tem como função a delimitação de fronteiras entre campo-cidade. No polo oposto, por sua vez, estão os que já pensaram em viver na cidade (V-test $=3.5$, coord2: .25 ) e os que apresentam valores individuais (cluster 3) (V-test $=2.6$, coord2: .14), denotando que as dificuldades da vida no campo influenciam as reflexões acerca da mobilidade social, processo peculiar aos indivíduos que se localizam mais caracteristicamente no plano dos valores individuais (TAJFEL, 1982; 1983).

\section{Ancoragem psicossocial de cidade}

Sobre o polo negativo do primeiro fator (Centro dos recursos), nenhuma das variáveis foi projetada de forma significativa, o que sugere que esse conjunto de significados tende a uma maior generalização no grupo rural. A esse conceito de cidade, opõe-se a imagem de um Modo de vida ruim, que é representado, principalmente, pelos indivíduos que não recomendam a vida neste território (V-test $=3.0$, coord1: .31) e que já viveram em áreas urbanas, o que indica maior possibilidade de comparação entre os modos de vida do campo e da cidade.

Para o segundo fator, no conjunto de significados concernentes à Dimensão instrumental estão os que já sofreram preconceito (V-test $=-3.6$, coord2: -.17 ), os que não recomendam a vida na cidade ( $V$-test $=-3.7$, coord2: -.38 ) e os sujeitos do cluster 1 (valores comunitários-endogrupais) ( $V$-test $=-2.1$, coord2: -.07 ). Os participantes que nunca pensaram em viver na cidade ( $V$-test $=3.2$, coord2: .08), não sofreram preconceito ( $V$-test $=3.6$, coord2: .09) e os sujeitos do cluster 2 (valores intergrupais) ( $V$-test $=-2.6$, coord2: .17) vincularam-se aos significados que retratam a cidade a partir de componentes concretos ou figurativos.

Discutindo os princípios organizadores das representações de rural e cidade

Os processos relacionados à identificação (a) do campo semântico associado 
aos objetos rural e cidade, (b) dos princípios organizadores das diferenças individuais e (c) dos processos de ancoragem do conteúdo representacional (DOISE, CLÉMENCE e LORENZI-CIOLDI, 1995), que compõem o "paradigma das três fases" (PALMONARI, 2009), serão discutidos, tendo como referência as antinomias que regulam os significados que constituem os dois objetos (MARKOVÁ, 1999; 2006), cuja manifestação pode ser conferida na polaridade temática dos fatores extraídos (CLÉMENCE, 2003).

Em consonância com a acepção de Vala (1996), que condiciona a abordagem da representação ao "sujeito social desta representação, ou seja, o grupo social em que ancora ou as identidades sociais que Ihes subjazem" (p. 150), é necessário esclarecer que, neste trabalho, a ideia de comunidade é conceitualmente equivalente à de grupo social e psicológico de pertencimento (SPELTINI e PALMONARI, 1999). Em pesquisa anterior com integrantes dessa mesma comunidade, Bonomo e Souza (2010) constataram a elaboração de um sentimento compartilhado de comunalidade, condição que se reflete no conjunto de resultados analisados no presente estudo e evidencia uma condição basilar para o estudo dos objetos sociais, segundo a teoria das representações sociais: o caráter compartilhado das relações sociais entre os indivíduos que constituem os sujeitos da representação.

Conforme Berti, Pivetti e Melotti (2008), cada cluster de indivíduos proveniente do campo semântico do objeto investigado indica a existência de uma representação distinta, proposição que pode ser reconhecida por meio da equivalência entre os clusters (críticos-rural, críticos-cidade, concretos-rural, concretos-cidade, engajados-rural e usuários-cidade) e seus respectivos campos de significação no plano fatorial (Figuras 1 e 2).

Na Tabela 6, pode-se visualizar as dimensões que qualificam as representações de cada objeto: (1) na dimensão figurativa, apresentam-se as representações do rural como mundo natural, e da cidade como mundo artificial; (2) na dimensão sociabilidade, o rural é significado como vida feliz, e a cidade como vida ruim; e, por fim, (3) na dimensão sustentabilidade, o rural é visto como quase autossuficiente e a cidade como centro dos recursos. As antinomias que operam nos princípios organizadores das representações de rural e cidade fornecem evidências de sua interdependência constitutiva e funcional.

Na primeira fase da análise do campo semântico associado aos objetos abordados (Tabela 1), o conteúdo já indicava a presença de elementos polarizados, possivelmente referenciados pela lógica do favorecimento endogrupal (TAJFEL, 1982; 1983). Seguindo os três níveis de análise das ancoragens dos elementos de representação, a confluência entre as dimensões identitárias e representacionais do processo de significação dos objetos rural e cidade foi sendo verifica- 
9. Para as categorias que foram compostas por dois polos (Modo de vida/rural e Os recursos/cidade), selecionou-se a variável com maior valor $V$-test $\geq|2|$ para integrar o conjunto de resultados gerais que organizam o campo representacional de rural e cidade. da com maior consistência e detalhamento.

Tabela 6 - Composição do campo representacional de rural e cidade ${ }^{9}$

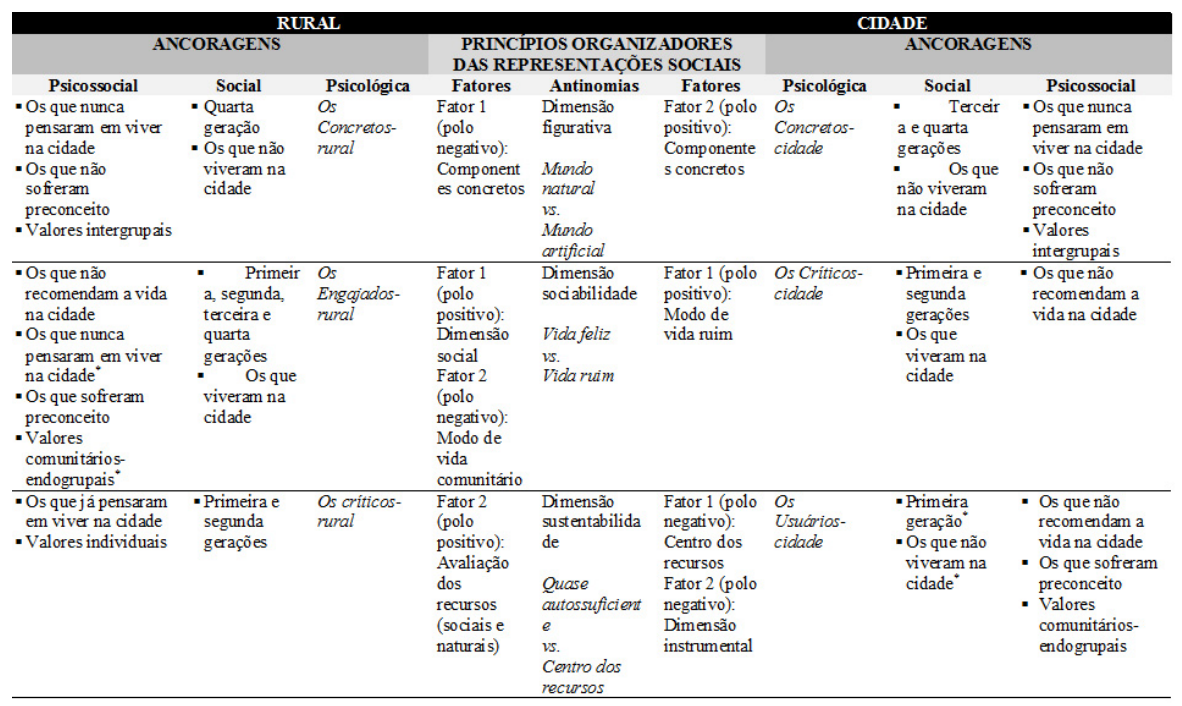

Para as categorias que foram compostas por dois polos (Modo de vida/rural e Os recursos/cidade), selecionou-se a variável com maior valor V-test $\geq|2|$ para integrar o conjunto de resultados gerais que organizam o campo representacional de rural e cidade

A partir das dimensões indicadas na Tabela 6 (figurativa, sociabilidade e sustentabilidade), foram agrupados os principais resultados que caracterizam a elaboração das representações sociais de rural e cidade. Sugere-se que a leitura do referido material seja iniciada a partir da coluna central Princípios organizadores das representações sociais. Consta, à esquerda, a síntese do campo representacional do rural; e à direita, a síntese referente à cidade.

O primeiro princípio organizador das representações, mundo natural vs. mundo artificial, foi ancorado nas mesmas variáveis para os dois objetos abordados (exceto pela presença da terceira geração, especificamente na ancoragem social de cidade). Os indivíduos que nunca pensaram em migrar para a cidade, que sempre viveram no campo e que não sofreram situações de preconceito por serem reconhecidos como pessoas do meio rural, designados os concretos, concorrem significativamente para a elaboração das representações de rural e cidade alicerçadas na descrição objetiva do espaço, o que sugere uma imagem mais simplificada das duas realidades. Provavelmente, vivenciaram menos situ- 
ações que poderiam favorecer o processo de comparação social campo-cidade e foram menos provocados a se posicionar de forma distintiva em frente à cidade, o que pode ter resultado em recursos simbólicos menos avaliativos ou afetivos. Apesar dessa representação de cidade não conter elementos indicativos de ameaça e perigo, é importante destacar a clara distinção entre o conteúdo que referencia o campo representacional do rural e da cidade como mundos distintos. A diferenciação social, conforme Lloyd e Duveen (1990) destacam, indica a função grupal no processo de ideologização dos dois objetos ao longo da socialização das novas gerações da comunidade que crescem inseridas em um mundo que separa campo e cidade, camponeses e citadinos.

Os engajados-rural e os críticos-cidade anunciam o segundo princípio organizador das representações de rural e cidade, como objetos em relação (MARKOVÁ, 1999; 2006): "vida feliz vs. vida ruim". A vida ruim na cidade, especialmente destacada pelos participantes que já viveram em áreas urbanas e não recomendam a vida no contexto urbano, contrasta com a vida feliz no meio rural, o que é compartilhado por todas as gerações da comunidade. A cidade como ameaça é reforçada, principalmente, pelas primeiras gerações, responsáveis pela transmissão para as novas gerações dos recursos simbólicos que distinguem os dois universos, com o propósito de evitar o abandono do grupo. Também contribuem para o rural como vida feliz os indivíduos que nunca pensaram em migrar para centros urbanos, os que já sofreram preconceito por serem identificados como camponeses e ainda os que possuem valores fundamentalmente comunitários (endogrupais).

Tomando como referência o conjunto de resultados que organiza a representação a partir da oposição vida feliz/vida ruim, pode-se considerar que a experiência de preconceito e a presença dos migrados que retornaram à comunidade contribuem de forma positiva para a identidade social do grupo rural, fortalecendo o sentido de comunalidade. Os indivíduos incluídos nessa condição acrescentam novos recursos ao imaginário grupal, posto que, ao relatarem as experiências negativas com o contexto urbano, contribuem para justificar e fortalecer a fronteira entre os dois territórios.

O terceiro e último princípio, quase autossuficiente vs. centro dos recursos, abre a possibilidade de discussão sobre as implicações da elaboração das imagens endo e exogrupal para a tomada de posição de seus membros em relação a temas polêmicos, como a migração e a reprodução social da comunidade.

O conceito de um território completo, com recursos naturais e sociais disponíveis ao pleno desenvolvimento e manutenção do modo de vida na comunidade rural, é fragilizado. Os críticos-rural incorporam ao sistema de significação os problemas de ordem econômica enfrentados no campo e responsabilizam a ci- 
dade pela falta de políticas públicas que minimizem esse contexto desfavorável. Os indivíduos associados ao rural como quase autossuficiente possuem valores mais individuais e já pensaram em viver em áreas urbanas. A comparação entre os recursos existentes na cidade e os escassos recursos do rural contribui para que a emigração seja cogitada como uma alternativa para esses indivíduos. Ainda em relação à representação do rural, a preocupação com a continuidade do modo de vida comunitário-familiar, manifestada, principalmente, pela primeira e pela segunda gerações, favorece a associação desses grupos geracionais ao conjunto de significados que retratam a avaliação dos recursos (sociais e naturais) do território, visto que esse grupo posiciona-se favoravelmente à permanência no meio rural.

Os usuários-cidade, por sua vez, estabelecem com o objeto cidade uma relação instrumental. Embora a imagem de centro dos recursos possa sugerir uma possível idealização do urbano, a análise dos processos de ancoragem indica que os indivíduos que participam da elaboração dessa representação de cidade não se identificam com o contexto urbano. Compõem essa imagem do objeto cidade os participantes que possuem como centrais os valores comunitários-endogrupais que se organizam em torno da ideia de comunalidade, os que não recomendam o modo de vida na cidade e os que afirmaram já ter sofrido preconceito por serem reconhecidos como pessoas do meio rural. Destaca-se ainda que a geração associada a essa representação de cidade é principalmente a primeira, dado que a referida representação fortalece esse grupo geracional como defensor do modo de vida rural.

Focalizando exclusivamente os clusters referentes ao segundo e ao terceiro princípios organizadores das representações sociais (Tabela 6), pode-se constatar que, no rural, os críticos estão vinculados à avaliação dos recursos enquanto que, na cidade, estes associam-se à avaliação negativa do modo de vida citadino. Já o modo de vida rural é significado de forma positiva pelos engajados, sendo destacada a sua organização social comunitária. A cidade, mais uma vez, é afastada: os usuários retratam os serviços necessários aos cidadãos rurais, estabelecendo uma relação utilitária com este espaço ("fazer o que tem que ser feito e vir embora"). Esse tipo de relação entre as dimensões sociabilidade e instrumental parece indicar a construção do seguinte sistema interpretativo: "Somos felizes no meio rural e o que não é bom por aqui é culpa da cidade. Por sua vez, lá na cidade eles têm os recursos que nos faltam, mas a vida deles é ruim". O resultado dessa equação avaliativa, cuja lógica apresenta-se regida por princípios identitários, parece previsível: a predileção endogrupal prevalece.

Na abordagem não consensual (DOISE, 1992; 2002a), a representação social é compreendida como um conjunto de pontos de vista divergentes que, regidos por determinados princípios gerais, compõem a sua "espinha dorsal" (RATEAU, 
2004). A partir desse quadro conceitual, a análise das diferentes modalidades de ancoragem sobre os objetos de representação de rural e cidade possibilitou a identificação de núcleos semânticos particularizados que formam representações específicas sobre cada objeto, de acordo com as diferentes inserções dos integrantes da comunidade. As tomadas de posição individuais em relação aos significados associados a determinado objeto reforçam, portanto, a interpretação de que as "pessoas têm uma participação activa na construção das suas representações, tentando conferir um sentido aos grupos sociais a que pertencem" (AMARAL, 1997, p. 316).

$\mathrm{Na}$ análise da ancoragem social dos objetos rural e cidade, a variável sexo não foi significativa para a constituição do campo representacional, confirmando a proposição de Doise e Devos (1999), de que "quanto mais um nível de categorização é saliente, mais os outros níveis tornam-se ocultos" (p. 15 - tradução nossa). É possível que a importância da categoria sexo tenha sido reduzida estrategicamente, visando tornar o grupo mais homogêneo, a fim de estabelecer mecanismos simbólicos mais eficazes para a diferenciação em relação ao exogrupo. Sobre essa necessidade de elaboração de uma imagem, que implica distinção intergrupal, Vala e Lima (2002) esclarecem: "a percepção de semelhança de valores, crenças ou atitudes entre grupos constitui uma ameaça à identidade desses grupos. Consequentemente, será a percepção de semelhança, e não a percepção da diferença, que pode facilitar a discriminação intergrupal" (p. 185).

Por fim, cabe ressaltar que os resultados apresentados reforçam a interpretação de integração entre os processos de identidade e representações intergrupais (BREAKWELL, 1993; DOISE, 2002a e 2002b; TAFJEL, 1982 e 1983; VALA, 1997). No que se refere às funções das representações encontradas para o grupo rural, é importante resgatar as hipóteses moscovicianas ( $\mathrm{MOSCOVICl,} \mathrm{2005):} \mathrm{(a)} \mathrm{se-}$ gundo o interesse do endogrupo rural, as representações foram elaboradas de modo a favorecer o seu posicionamento no campo de significação, selecionando elementos que o qualificaram de maneira positiva, enquanto à cidade foram associados elementos que a desfavoreceram no plano das relações simbólicas de poder; (b) a fim de assegurar a condição de equilíbrio interno, especialmente fragilizado pela ausência de recursos, a imagem endogrupal foi supervalorizada em contraposição à cidade, caracterizada como "centro dos recursos", mas portadora de um modo de vida ruim, afastando a possibilidade de identificação dos membros do grupo rural com a sociabilidade urbana; e (c) a função das representações como sistema interpretativo, que seleciona e processa as informações que chegam do ambiente externo, controla a realidade dos indivíduos em relação ao grupo de pertencimento. Expressão dessa última função é o processo de ideologização dos objetos rural e cidade, como contextos de pertencimento e de oposição, respectivamente, o qual ficou evidente por meio 
da análise geracional. A transmissão de elementos que promovam a identificação com o endogrupo e o afastamento da cidade, por meio de representações dicotômicas e polarizadas, parece fundamentar o processo de socialização. Por meio das representações sobre os dois universos, rural e cidade, a distintividade do endogrupo pode ser reforçada e tornar-se mais complexa e mais forte em função de experiências que indicam a existência de preconceito ou da migração malsucedida. As referidas representações confluem para a elaboração de estratégias grupais que visam preservar o modo de vida da comunidade e garantir a sobrevivência de sua sociabilidade por meio das novas gerações.

\section{Considerações finais}

O estudo versou sobre a composição do campo representacional de rural e cidade a partir da análise das ancoragens psicológica, social e psicossocial. A proposição teórico-metodológica apresentou-se como recurso apropriado à investigação dos significados que concorrem à elaboração do campo semântico das representações abordadas, pois favoreceu a identificação não apenas do seu conteúdo interno, mas fundamentalmente dos princípios que confluem e articulam significados em torno da experiência e da história dos indivíduos e de seus grupos (DOISE, 1992, 2002a e 2002b). Assim, neste estudo, considerando que os objetos em questão guardam profunda relação com a caracterização do próprio grupo rural, partiu-se do sujeito da representação, a fim de conhecer os significados que constituem sua realidade, processo que retorna a análise ao ponto de partida, coração do fenômeno social vivido pelos integrantes da comunidade rural, a construção de sua identidade social.

Os resultados deste estudo mostraram como a inserção geracional, a existência de expectativas relacionadas à migração, a vivência exclusiva no campo ou o fato de já ter vivido em áreas urbanas, bem como a experiência de preconceito e os valores vinculados ao rural, participam com diferentes matizes da elaboração de representações sociais de rural e cidade. Foi possível constatar que quanto menor a experiência de contato com a cidade, mais figurativa e simplificada é a representação dos dois objetos; e, por sua vez, quanto maior a comparação campo-cidade, especialmente a partir de situações conflitivas vivenciadas, mais elaboradas (avaliativas e afetivas) tornam-se as representações dos referidos objetos, denotando a importância do conflito para a construção e fortalecimento da identidade social do grupo.

Entre as possíveis questões decorrentes das análises e resultados evidenciados, permanece a indagação direcionada à categoria sexo, abordada no processo de ancoragem social das representações. Conforme dados analisados, essa variá- 
vel não contribui de forma significativa para a elaboração das representações de rural e cidade, sugerindo a dissolução do posicionamento dos indivíduos a partir dos grupos masculino e feminino em favor da categoria rural, saliente no processo estudado. Neste sentido, seria interessante o desenvolvimento de novos estudos que investiguem em maior profundidade os processos de categorização endogrupais baseados na categoria sexo e sua relação com a identidade do grupo.

Referências bibliográficas

ABRIC, J. C. "De l'importance des représentations sociales dans les problèmes de exclusion sociale". In Exclusion sociale, insertion et prévention. Ramonville Saint-Agne: érès, 2003

ALMEIDA, A. M. O. "Abordagem societal das representações sociais". Sociedade e Estado, 24(3), 2009, p. 713-737.

AMARAL, V. "Níveis de análise da ancoragem das representações sociais da inteligência e do seu desenvolvimento: Das posições sociais objectivas às identidades sociais". Análise Psicológica, 2(15), 1997, p. 305-317.

BERTI, C.; PIVETTI, M.; MELOTTI, G. "Dal 'public understanding of science' allo 'scientific understanding of public': rappresentazioni sociali del progetto genoma umano". Psicologia sociale, 2, 2008, p. 283-306.

BONOMO, M.; SOUZA, L. "Do território à cultura comunitária: representações sociais de comunidade". Revista Electrónica de Psicología Política, 23, 2010, p. 1-50.

BREAKWELL, G. M. "Integrating paradigms, methodological implications". In Breakwell, G. M.; Canter, D. V. (Eds.). Empirical Approaches to Social Representations. London: Clarendon Press-Oxford, 1993.

BROWN, R. Psicologia sociale del pregiudizio. Bologna: II Mulino, 1997.

CLÉMENCE, A. "L'analyse des príncipes organisateurs des représentations sociales." In Moscovici, S.; Buschini, F. (Orgs.). Les méthodes des sciences humaines. Paris: Puf Fondamental, 2003.

DESCHAMPS, J. C.; MOLINER, P. A identidade em psicologia social - Dos processos identitários às representações sociais. Petrópolis, RJ: Editora Vozes, 2009.

DOISE, W. "L'ancrage dans les études sur les représentations socials". Bulletin de Psychologie, 45, 1992, p. 189-195. 
DOISE, W. La forza delle idee - rappresentazioni sociali e diritti umani. Bologna: Il Mulino, 2002a.

DOISE, W. "Da psicologia social à psicologia societal”. Psicologia: teoria e pesquisa, 18(1), 2002b, p. 27-35.

DOISE, W.; DEVOS, T. Identite et interdependance: pour une psychologie sociale de l'union europeenne. Psychologie et société, 1, 1999, 11-27.

DOISE, W.; Clémence, A.; LORENZI-CIOLDI, F. Rappresentazioni sociali e analisi dei dati. Bologna: Il Mulino, 1995.

DURHAM, E. R. A dinâmica da cultura: ensaios de antropologia. São Paulo: Cosac Naify, 2004.

Galli, I. La teoria delle rappresentazioni sociali. Bologna: II Mulino, 2006.

LACERDA, M.; PEREIRA, C.; CAMINO, L. "Um estudo sobre o preconceito contra homossexuais na perspectiva das representações sociais". Psicologia: Reflexão e Crítica, 15, 2002, p. 165-178.

LEBART, L.; Morineau, A.; BECUE, M.; Haeusler. L. SPAD-T-Manuel de l'utilisateur. France: Cisia - Centre International de statistique et d'informatique appliquées, 1994.

LLOYD, B.; DUVEEN, G. "A semiotic analysis of the development of social representations of gender". In Duveen, G; Lloyd, B. (Eds.). Social Representations and the Development of Knowledge. Cambridge: C.U.P, 1990.

MARKOVÁ, I. Sur la reconnaissance sociale. Psychologie et société, 1999, 1, p. 55-80.

MARKOVÁ, I. Dialogicidade e representações sociais - as dinâmicas da mente. Petrópolis: Editora Vozes, 2006.

MAZZARA, B. M. "Relazioni interetniche e construzione sociale del pregiudizio". In Zani, B (Org.). Le dimensioni della psicologia sociale. Roma: La Nuova Italia Scientifica, 1996.

MOSCOVICl, S. A máquina de fazer deuses - sociologia e psicologia. Rio de Janeiro: Imago Ed., 1990.

Moscovici, S. Le rappresentazioni sociali. Bologna: II Mulino, 2005.

MOSCOVICI, S.; DOISE, W. Dissensi e consensi - una teoria generale delle decisioni collettive. Bologna: II Mulino, 1992. 
PALMONARI, A; ZANI, B. "Les études de communautés". In Moscovici, S.; Buschini, F. (Orgs.) Les méthodes des sciences humaines. França: Puf Fondamental, 2003.

PALMONARI, A. Processi simbolici e dinamiche sociali. Bologna: II Mulino, 1995.

PALMONARI, A. "A importância da Teoria das Representações Sociais para a Psicologia Social." In Almeida, A. M. O.; Jodelet, D. (Orgs.) Representações sociais: interdisciplinaridade e diversidade de paradigmas. Brasília: Thesaurus, 1999.

PEREIRA, A. S. L. S. Representações sociais do homossexualismo e preconceito contra homossexuais. Dissertação de Mestrado em Psicologia, Universidade Católica de Goiás, 2004.

PEREIRA, C.; CAMINO, L. Representações sociais, envolvimento nos direitos humanos e ideologia política em universitários de João Pessoa. Psicologia: Reflexão e Crítica, 16(3), 2003, p. 447-460.

PREZZA, M.; PACILLI, M. G. "Il senso di comunità". In Prezza, M.; Santinello, M. (Orgs.) Conoscere la comunità - l'analisi degli ambienti di vita quotidiana. Bologna: II Mulino, 2002.

RATEAU, P. “Organizing principles and central core of social representations empirical hypothesis". Arquivos Brasileiros de Psicologia, 56(1), 2004, 82-92.

SAWAIA, B. B. "Comunidade: a apropriação de um conceito tão antigo quanto a humanidade". In Campos, R. H. F. (Org.) Psicologia social comunitária: da solidariedade à autonomia. Petrópolis: Editora Vozes, 1996.

SPELTINI, G.; PALMONARI, A. I gruppi sociali. Bologna: II Mulino, 1999.

STROPASOLAS, V. L. "O Valor (do) casamento na agricultura familiar". Estudos Feministas, Florianópolis, 12(1), 2004, 253-267.

TAJFEL, H. Grupos humanos e categorias sociais I. Lisboa: Livros Horizonte, 1982.

TAJFEL, H. Grupos humanos e categorias sociais II. Lisboa: Livros Horizonte, 1983.

VALA, J.; Lima, M. "Individualismo meritocrático, diferenciação, cultural e racismo”. Análise Social, 37(162), 2002, 181-207.

VALA, J. "As representações sociais no quadro dos paradigmas e metáforas da psicologia social". In Camino, L (Org.) O Conhecimento do outro e a construção da realidade social. João Pessoa: Editora Universitária, 1996.

VALA, J. "Representações sociais e percepções intergrupais". Análise Social, 32(140), 1997, p. 7-29. 
VEIGA, J. E. A atualidade da contradição urbano-rural. Análise Territorial da Bahia Rural. Série de Estudos e Pesquisas, 71, 2004.

WACHELKE, J. F. R.; CAMARGO, B. V.; Hazan, J. V.; SOARES, D. R., OLIVEIRA, L. T. P.; REYNAUD, P. D. Princípios organizadores da representação social do envelhecimento: dados coletados via internet. Estudos de Psicologia, 13(2), 2008, p. 107-116. 